Revue Europeene de Psychologie AppliqueeVolume 67, Issue 3, May 2017, Pages 117-124

\title{
The effect of belief in weight controllability on anti-fat attitudes: An experimental manipulation(Article)
}

\section{[Effet de la croyance en la possibilité de contrôler son poids sur les attitudes envers les personnes en surcharge pondérale : une expérimentation]}

- Ksinan, A.J. ${ }^{\mathrm{a} E m a i l}$ Author,

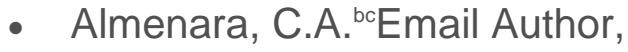

- Vaculik, M. ${ }^{\mathrm{d} E m a i l}$ Author

- View Correspondence (jump link)

- aUniversity of Kentucky, Department of Family Sciences, University of Kentucky, 160 Funkhouser Drive, Lexington, KY, United States

- 'Dasaryk University, Institute for Research on Children, Youth and Family (IVMDR), Department of Psychology, Faculty of Social Studies, Masaryk University, Joštova, 10, Brno, Czech Republic

- 'Universidad Peruana de Ciencias Aplicadas (UPC), Faculty of Psychology, Av. Alameda San Marcos, s/n, Lima, Peru

View additional affiliations_

Abstract_View references (53)

Introduction Anti-fat attitudes reflect a type of discrimination on the basis of body weight and are one of the last accepted types of social stigma. Objective To evaluate the effect of exposure to priming messages about the causes of obesity on attitudes toward fat people. Method Participants $(n=580, M$ age $=22.19$, $64.1 \%$ female) were randomly assigned to one of three possible conditions and then provided responses on three AFA subscales: Dislike, Fear of fat, and Willpower. Results Priming participants with messages confirming/challenging the weight controllability belief was associated with higher/lower levels on Willpower respectively compared to the control group. Unexpectedly, participants in both confirming and challenging groups showed significantly higher scores on Fear of fat. No differences were found on scores indicating Dislike. Conclusion The current findings emphasize the effect of exposure to information about the causes of obesity on weight controllability beliefs. (C) 2016 Elsevier Masson SAS

Author keywords

- Anti-fat attitudes

- Obesity 
- Prejudice

- Weight bias

- Weight-controllability belief

- ISSN: 11629088

- Source Type: Journal

- Original language: English, French

- DOI: 10.1016/j.erap.2016.12.004

- Document Type: Article

- Publisher: Elsevier Masson SAS 